\title{
Predisposing factors for substance abuse among elderly people referring to Qazvin addiction treatment centers, Iran (2017)
}

\author{
F. Kazemi ${ }^{1}$, SA. Motalebi ${ }^{2}$, M. Mirzadeh ${ }^{3}, \underline{\text { F. Mohammadi }}^{2}$
}

\author{
${ }^{1}$ Student Research Committee, Qazvin University of Medical Sciences, Qazvin, Iran \\ ${ }^{2}$ Social Determinants of Health Research Center, Qazvin University of Medical Sciences, Qazvin, Iran \\ ${ }^{3}$ Metabolic Diseases Research Center, School of Medicine, Qazvin University of Medical Sciences, Qazvin, Iran \\ Corresponding Address: Fatemeh Mohammadi, Social Determinants of Health Research Center, Qazvin University of \\ Medical Sciences, Qazvin, Iran \\ Tel: +98-912-1824233; Email: mohammadi1508@gmail.com \\ Received: 18 Jul 2018; Accepted: 2 Oct 2018
}

\section{* Abstract}

Background: Drug abuse is one of the most important global issue that has become a psychological, social, and family disaster

Objective: The present study was aimed to determine the causes of substance abuse in the elderly. Methods: In this descriptive cross-sectional study, 120 addicted elderly people referred to addiction treatment centers of Qazvin, Iran were selected by convenience sampling in 2017. The demographic and researcher-made substance abuse tendency questionnaires were applied for data collection. Data were analyzed by descriptive statistics including frequency, percentage, mean and standard deviation.

Findings: The mean age and age of the onset of drug abuse were $58.83 \pm 8.91$ and $34.44 \pm 13.37$ years, respectively. The majority of the elderly were male (113 subjects, 94.1\%), and $102(85.1 \%)$ elders were married. Opium was the most common abused drug $(75.8 \%)$ and more than half of them (64.2\%) experienced drug discontinuation. Environmental factors were the important reason of intendancy towards drug abuse among elderly people.

Conclusion: In this study, the most important reason of drug abuse in the elderly people was environmental factors that were consisted; easy access to drug, lack of sports and recreational facilities and the presence of addicted friends.

Keywords: Aging, Drug abuse, Addiction, Opium

Citation: Kazemi F, Motalebi SA, Mirzadeh M, Mohammadi F. Predisposing factors for substance abuse among elderly people referring to Qazvin addiction treatment centers, Iran (2017). J Qazvin Univ Med Sci 2018; 22(5): 26-35. 


\section{علل تَرايش به سوء مصرف مواد در سالمندان مراجعه كننده به مراكز ترك اعتياد قزوين، ايران (1)q7)}

فاطمه كاظمى'، دكتر سيده آمنه مطلبى'، دكتر منير السادات ميرزاده"، دكتر فاطمه محمدى'

' كميته تحقيقات دانشجويى دانشخاه علوم يزشكى قزوين، قزوين، ايران

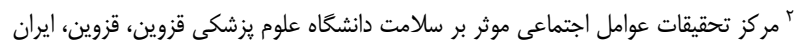

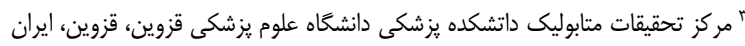

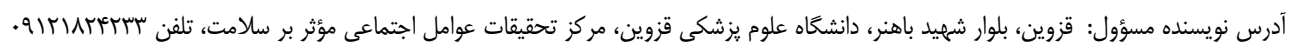

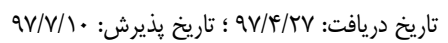

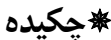

زمينه: سوء مصرف مواد مخدر يكى از مهمرترين مشكلات عصر حاضر است كه گستره جهـانى ييــا كـرده و بـهـ يـك معضـل روانسى، اجتمـاعى و خانوادگى تبديل شده است. هدف: مطالعه حاضر با هدف تعيين علل گر ايش بله سوء مصرف مواد در سالمندان انجام شد.

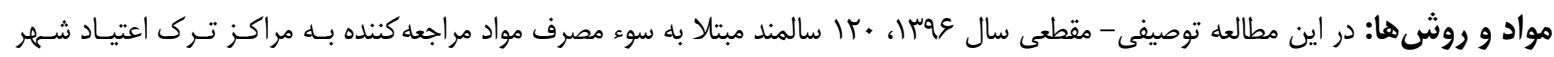

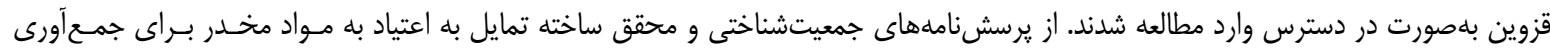

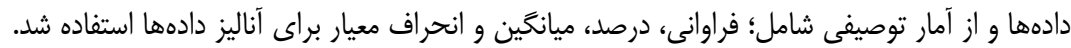

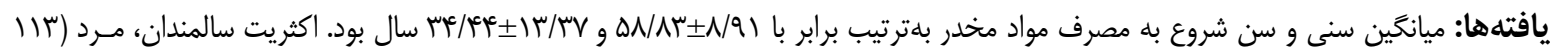

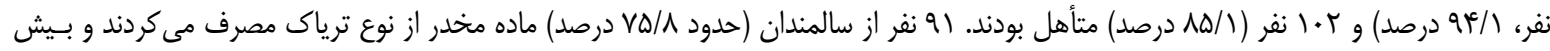

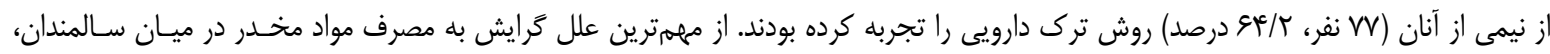
علل محيطى بود. نتيجهَ كيرى: در مطالعه حاضر، عوامل محيطى شامل؛ دسترسى آسان به مواد مخدر، عدم امكانـات تفريحسى و ورزشـى بــراى سـالمندان و وجـود

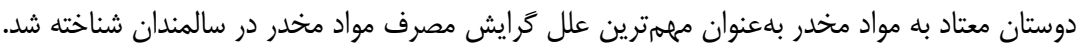

كليدوازهها: سالمندى، سوء مصرف مواد، اعتياد، مراكز درمان سوء مصرف مواد، ترياك

(2) مقدمه:

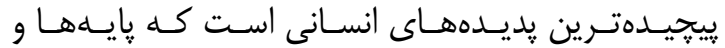

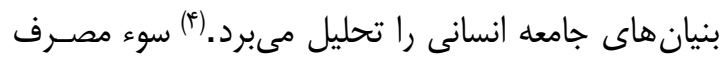
در ايران نيز يكى از مهمترين مسايل بهداشـتى، درمـانى،

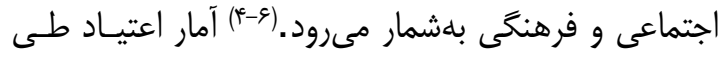

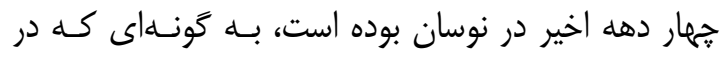

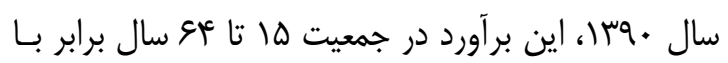

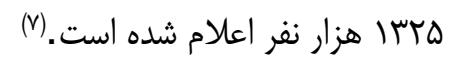
يكى از زروههايى كه بيش از ييش مسـتعد ابـتلا بـهـ سوء مصرف مواد هستند، سالمندان مىباشند. (^) بهطورى كه
وابستخَى به مواد دومين اختلال شايع روانسى در دنيـا مىباشد كه در كتابهاى روانيزشكى از آن تحت عنـوان

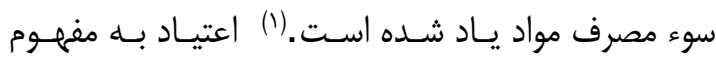

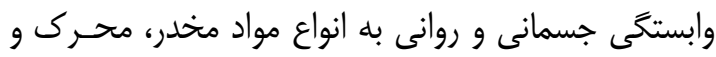
توهمزاست به نحوى كه در صورت كنار كذاشتن آن علايم ترك و سندرم محروميت از مواد در افـراد ظـاهر كَرددد.

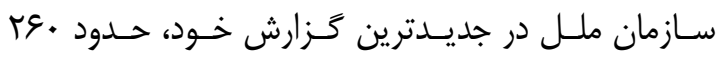
ميليون نفر را در دنيا درگير مواد مخدر مىداند.(") مصـرف درئ

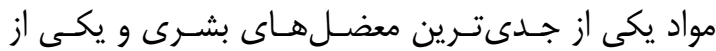


ديگر جمعيت سالمندان به سرعت در حال افـزايش اسـت،

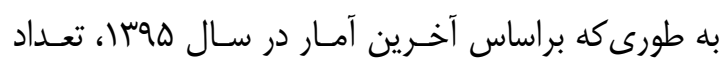

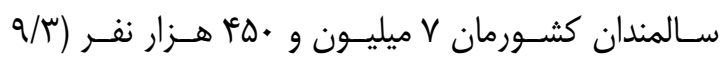

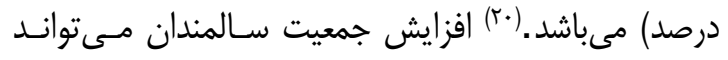

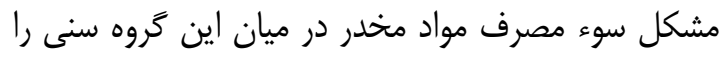

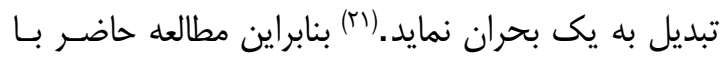

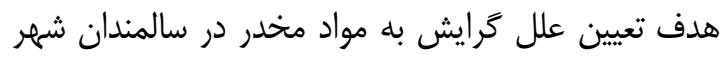

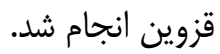

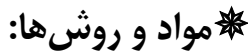

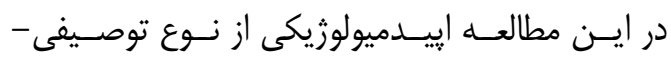
مقطعى، • rا سالمند مراجعل كننده به مراكز تـرك اعتيـاد شهر قزوين كه بلهورت در دسترس سال عوسا انتخـاب

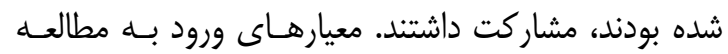
شامل؛ سن •ه سال و بالاتر، مصرف هر گُونه مــواد مخــدر

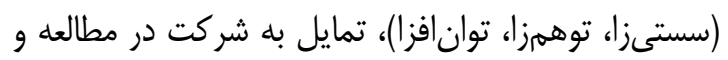

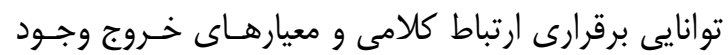
بيمارى حاد ناتوان كننده بود.

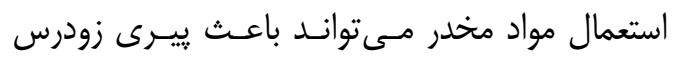

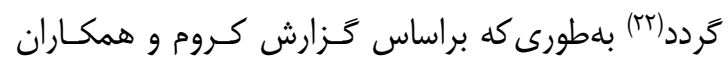
مخداد، (Y.IV)

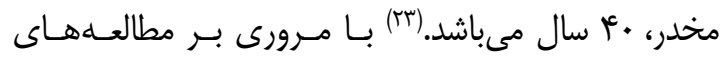

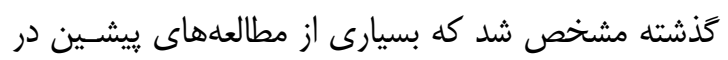

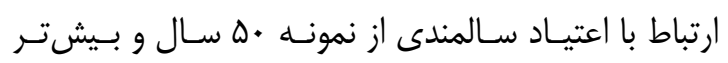
استفاده نمودند..TV با سن •ه سال و بالاتر وارد مطالعه شدند.

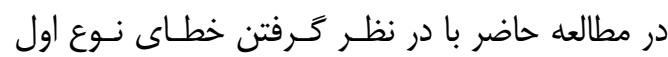

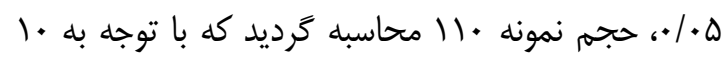

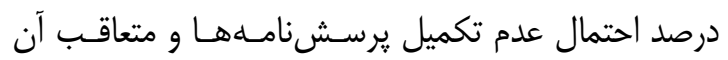

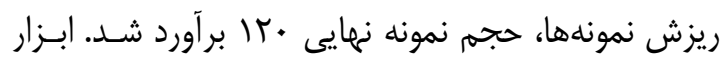

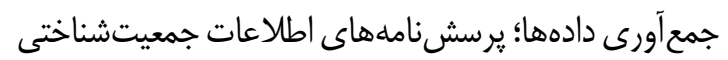
و محقق ساخته علل كرايش بله مصرف مواد مخدر بود. يرسشنامه اطلاعات جمعيـتشـناختى شـامل؛ سـن، جنس، وضـعيت تأهـل، شـل، سـطح تحصـــاتلات، تعـداد
در دهلهاى آينده، شــمار سـالمندان مصـرفكنتــهـ مـواد

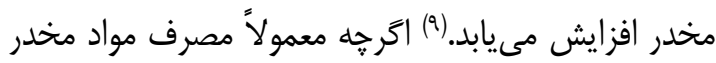

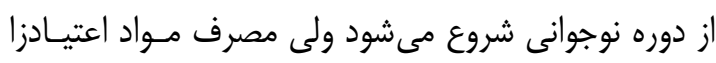

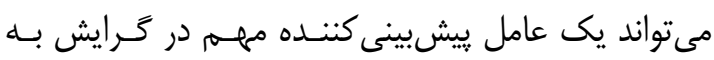

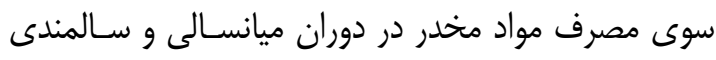

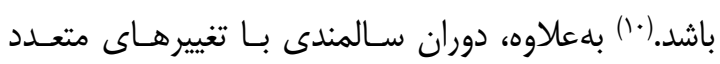

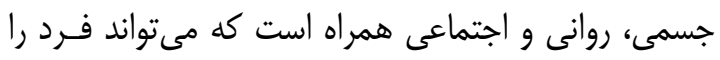

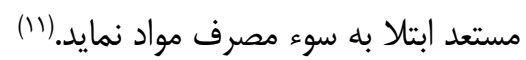

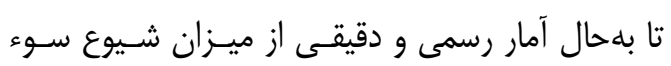

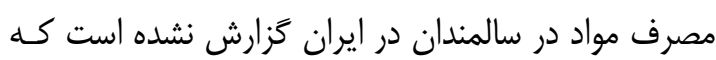

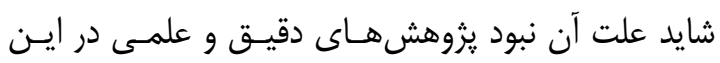

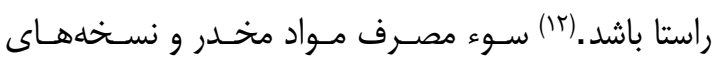

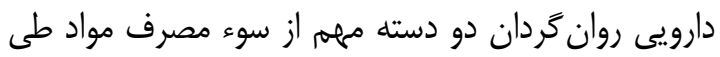

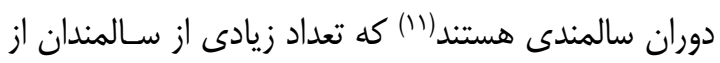

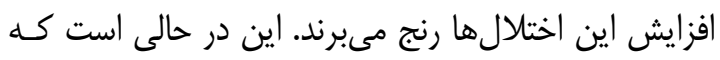

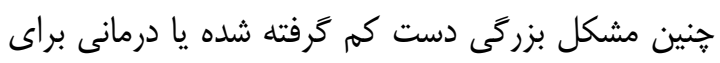

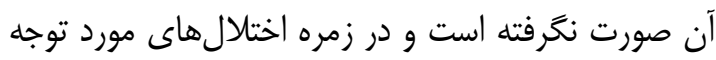

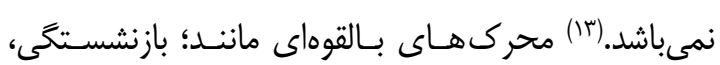

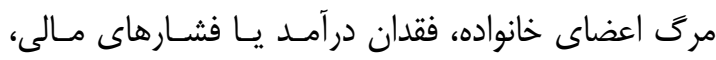

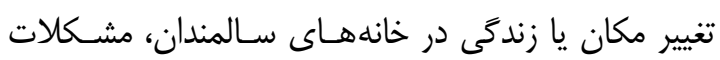

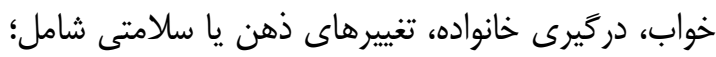

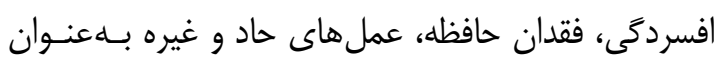

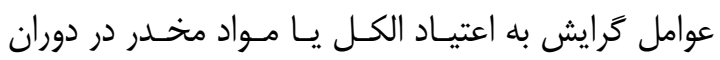
سالمندى معرفى شده است. نخستين كام در مبارزه با هر يديده اجتماعى شــناخت

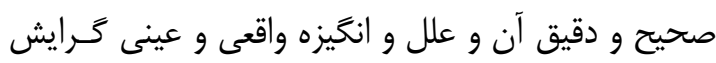

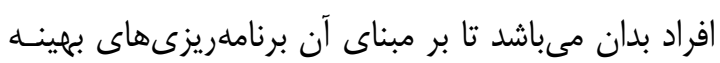

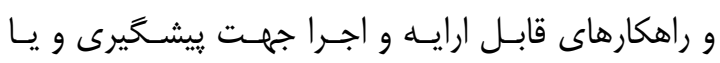

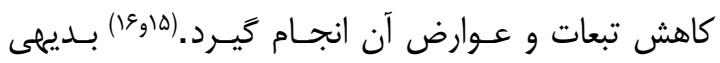

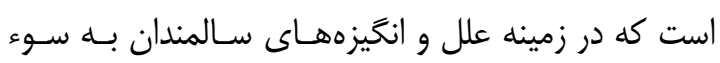

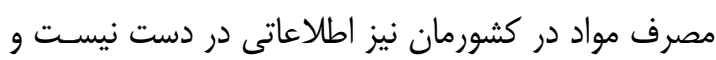

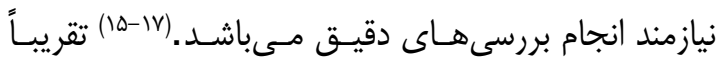

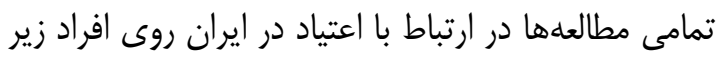

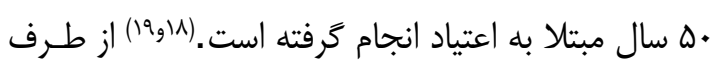




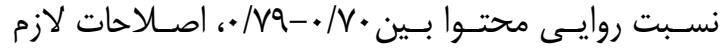
براساس ييشنهادهاى متخصصين انجام شدو.

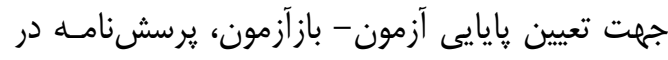

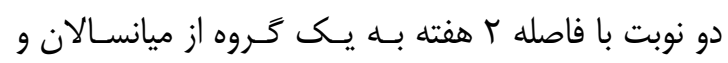

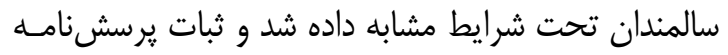

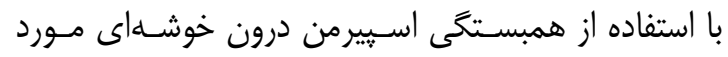

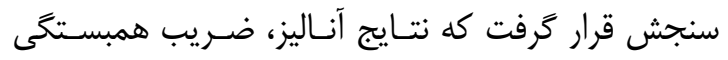

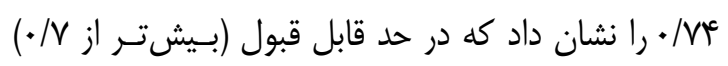

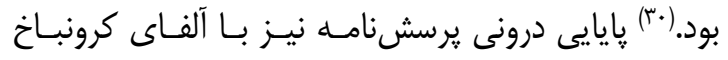
تأييد شد.

جدول ا - قسمتى از يرسشنامه محقق ساخته علل ترايش بله مواد مخدر

\begin{tabular}{|c|c|}
\hline 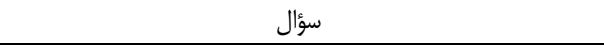 & حيطه ( - la \\
\hline جقدر مواد را با خانواده مصرف مى كنيد؟ & \multirow{3}{*}{ خانوادگى } \\
\hline آيا از افراد خانواده شما كسى وجود داشته كه در مورد مصرف مواد & \\
\hline مخدر توسط شما ابراز نخرانى كرده؟ & \\
\hline آيا در ميان دوستان صميمى شما معتاد به مصرف مواد مخدر يا & \multirow{3}{*}{ محيطى } \\
\hline 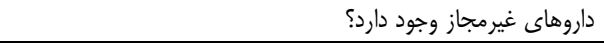 & \\
\hline آيا دسترسى به يكى يا حند نوع از مواد مخدر براى شما آسان است؟ & \\
\hline آيا جهت تسكين فشارهاى عصبى مواد مخدر مصرف مى كنيد؟ & 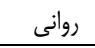 \\
\hline بهنظر شما مصرف مواد مخدر باعث افزايش اعتماد بلنفس مى شود؟ & \\
\hline به نظر شما، مصرف مواد مخدر، دردهاى مزمن را تسكين مىدهد؟ & \multirow{3}{*}{ 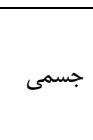 } \\
\hline آيا مصرف مواد مخدر، در بهبود بيمارىهاى مربوط به سالمندى مثل & \\
\hline ديابت يا مشكلات قلبى عروقى مؤثر است؟ & \\
\hline آيا نسبت به عوارض مصرف مواد مخدر آكَاهى داريد؟ & \multirow{2}{*}{ 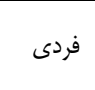 } \\
\hline آيا تحت فشار مالى هستيد؟ & \\
\hline آيا در مواقع مشكلات عميق شخصى به خداوند خود روى مىآوريد؟ & \multirow{2}{*}{ مذهبى } \\
\hline آيا احساس ترس از خداوند به شما دست مىدهد؟ & \\
\hline
\end{tabular}

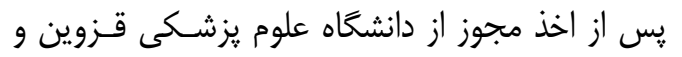

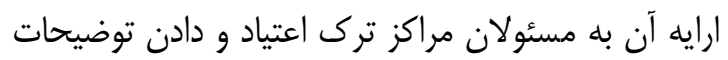

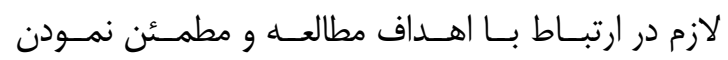
سالمندان در مورد محرمانه ماندن كليه اطلاعات، از آنـان

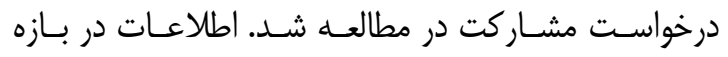

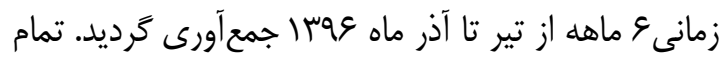

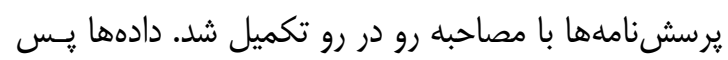

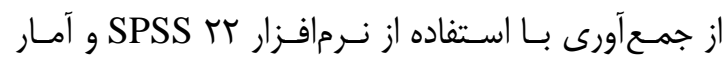
توصيفى مورد تجزيه و تحليل قرار گرفت.
فرزندان، وضعيت زندكى (تنها، با همسر، بــا فرزنـدان، بـاــا فاميل و با ديخران)، نوع مواد مصرفى، سن شروع مصرف،

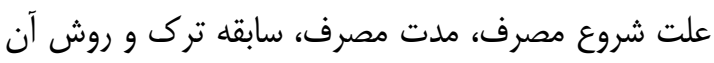

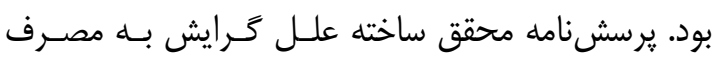

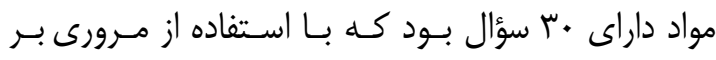

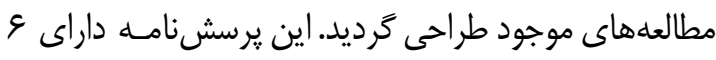

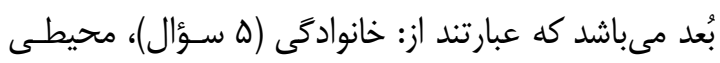

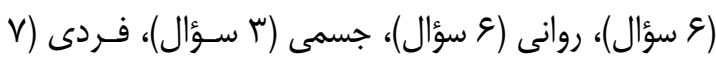

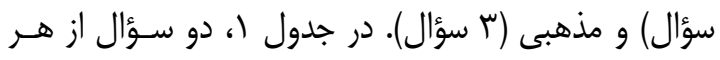

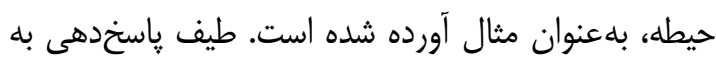

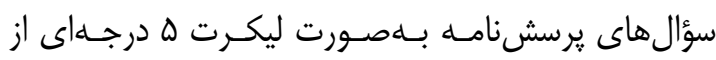

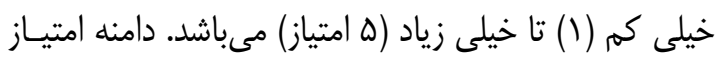

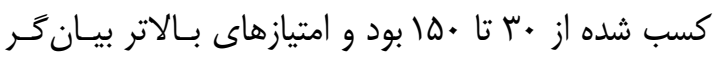

ميزان تمايل بيشتر شخص ياسخدهنده به اعت اعتياد بود.

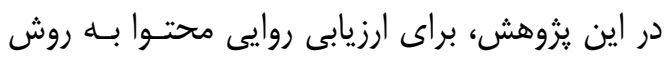

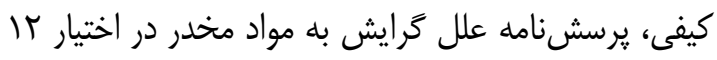

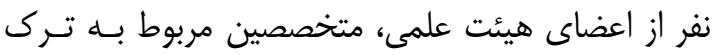

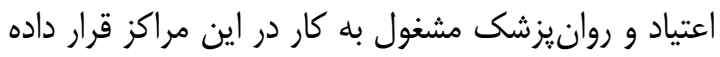

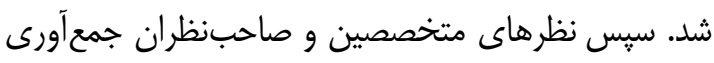

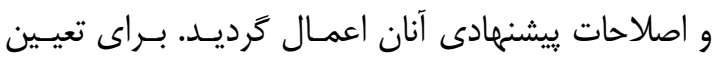

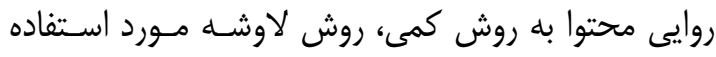

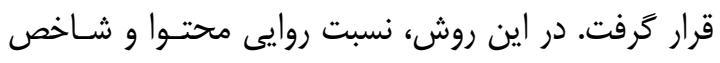

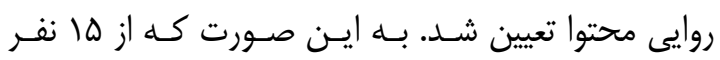

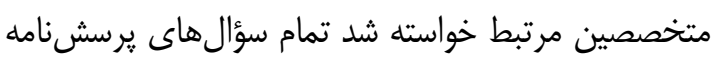
را براساس سه گزينـه؛ ضـرورى اسـت، مفيـــ اسـت امـا ضرورى نيست و ضرورتى ندارد، مورد ارزيابى قرار دهنــد.

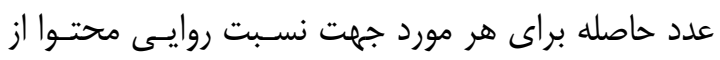

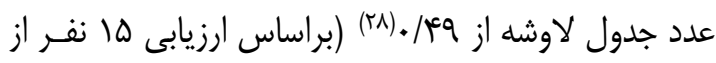

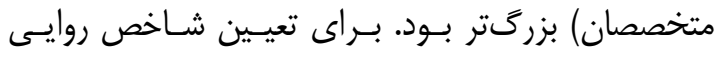

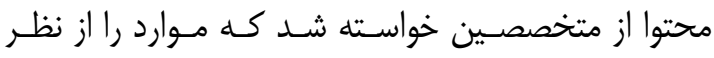

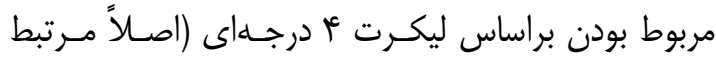
نيست، تا حدودى مرتبط است، نسبتاً مرتبط است و كاملاً

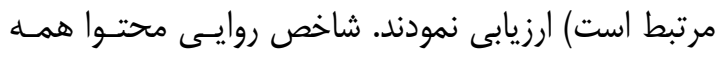

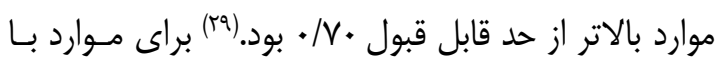


سال بود و باطور متوسـط شـركت كنتــدان مـــت زمـان

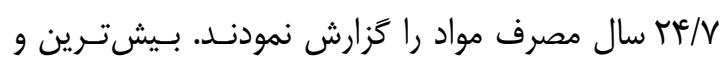

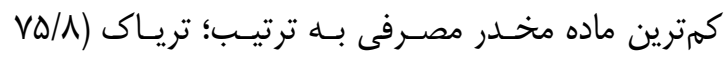

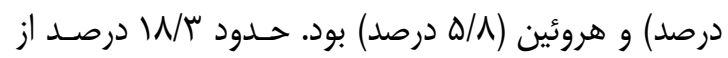
شركت كنندكان نيز مصرف مواد مخدر را بلهصورت تركيبى

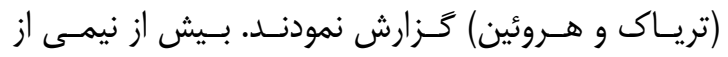

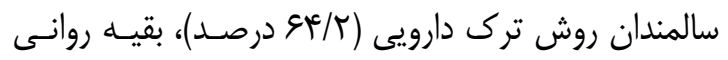

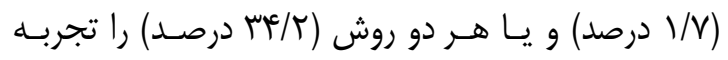
كرده بودند (جدول شماره r).

\section{㢳}

نتايج حاكى از آن است كـه اكثريـت سالمنــان مـرد

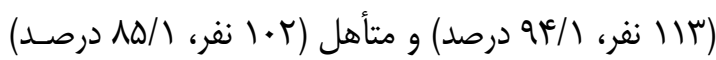

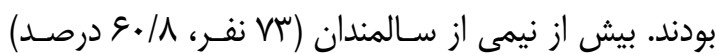

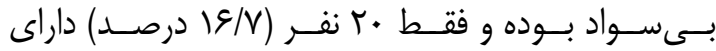

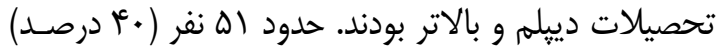

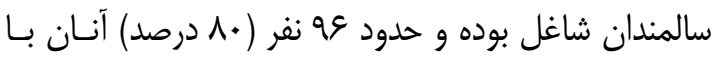

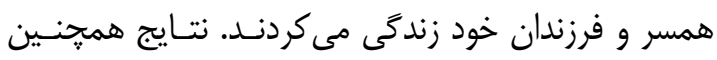

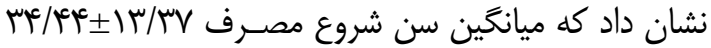

جدول r - توزيع فراوانى مشخصههاى جمعيتشناختى و سوء مصرف مواد در سالمندان مورد مطالعه

\begin{tabular}{|c|c|c|}
\hline (درصد) تعداد/ ميانگين +|نحراف معيار & \multicolumn{2}{|c|}{ متغيرها } \\
\hline 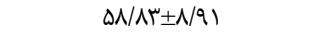 & \multicolumn{2}{|c|}{ سن (سال) } \\
\hline$M E / F Y \pm I T / T V$ & \multicolumn{2}{|c|}{ سن شروع مصرف (سال) } \\
\hline$T F / V G \pm I I / V \Lambda$ & \multicolumn{2}{|c|}{ مدت زمان مصرف (سال) } \\
\hline $11 \pi(95 / 1)$ & مرد & \multirow[b]{2}{*}{ 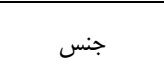 } \\
\hline$V(\Delta / q)$ & زن - ت ا & \\
\hline 每 & بيكار & \multirow{3}{*}{ 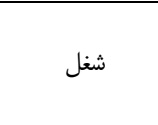 } \\
\hline DI $(F T / \Delta)$ & شاغل & \\
\hline$r \Phi(Y) / V)$ & بازنشسته & \\
\hline$V \Psi(\xi \cdot / \Lambda)$ & بـ بـواد & \multirow{3}{*}{ تحصيلات } \\
\hline$T r(T Y / \Delta)$ & سيكل & \\
\hline$r \cdot(\mid g / V)$ & دييلم و بالاتر & \\
\hline$r(T / \Delta)$ & بيوه & \multirow{4}{*}{ وضعيت تأهل } \\
\hline $11(9 / 1)$ & مطلقه & \\
\hline $\mathcal{F}(\mu / \mu)$ & مجرد مجر & \\
\hline I. $\mathrm{r}(\Lambda \Delta / \Lambda)$ & متأهل & \\
\hline$f(\Gamma / \mu)$ & 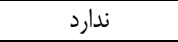 & \multirow{4}{*}{ ت ت تعداد فرزندان } \\
\hline 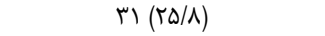 & ا تاץ & \\
\hline$\uparrow \wedge(\kappa \cdot)$ & كابان & \\
\hline$r V(\Gamma \cdot / \Lambda)$ & بيش از أ & \\
\hline$r \mu(19 / 1)$ & تنها & \multirow{3}{*}{ وضعيت زندگى } \\
\hline 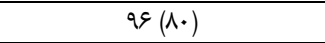 & با همسر و فرزندان & \\
\hline $1(\cdot / 9)$ & با فاميل & \\
\hline १) $(\mathrm{VQ} / \Lambda)$ & ترياك & \multirow{3}{*}{ مواد مصرفى } \\
\hline$\checkmark(\Delta / \wedge)$ & هروئين & \\
\hline$r(\mid N / r)$ & تركيبى & \\
\hline$r(I / V)$ & كنجكاوى & \multirow{6}{*}{ علل شروع مصرف } \\
\hline$r \cdot(T \Delta)$ & تفريحى & \\
\hline$\Delta Q(F \Delta / \Lambda)$ & مشكلات زندگى & \\
\hline$V(\Delta / \Lambda)$ & مشكلات جسمى & \\
\hline$M(I V / \Delta)$ & مشكلات روحى & \\
\hline$\Delta(F / T)$ & غيره & \\
\hline$W(\xi / r)$ & دارويى & \multirow{3}{*}{ روش ترى } \\
\hline$r(1 / V)$ & 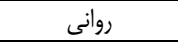 & \\
\hline$F(T / T)$ & هر دو & \\
\hline
\end{tabular}


مىتوان انتظار داشت كه طى سال هاى آتى شاهد مراجعهـ

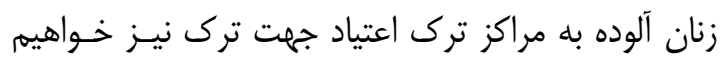

در مطالعه حاضر، شايعترين ماده مصرفى ترياك بـود

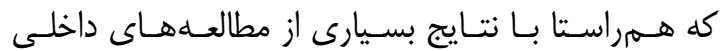

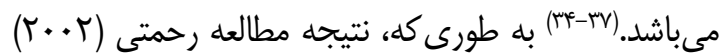

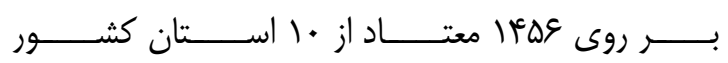

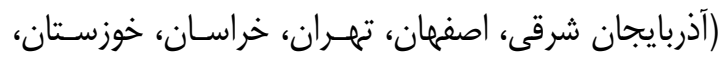

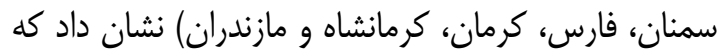

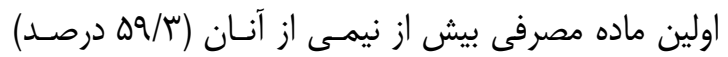

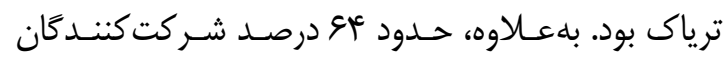
اظهار داشتند كه اغلب مصرف كنندكان ترياك، بزركسالان

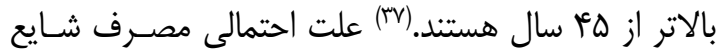

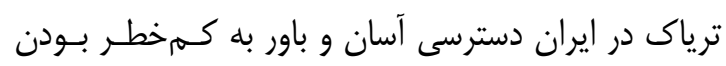

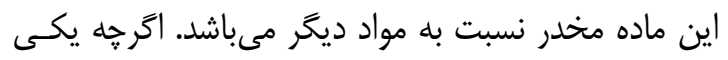

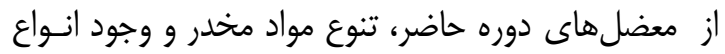
جديد و خطرناك و حس كنجكاوى جوانـان امـروز بــراى تجربه اين مواد جديد مى باشد.

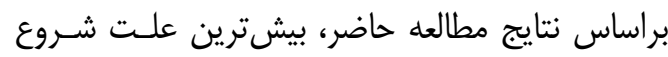

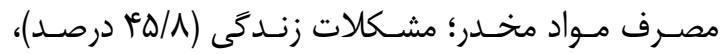

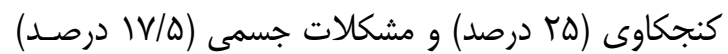

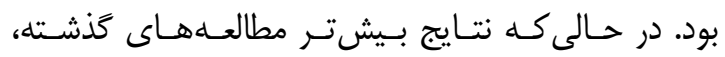

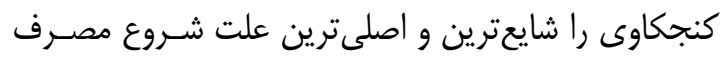

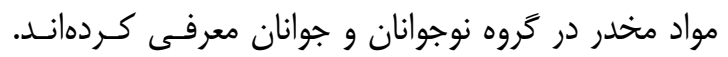
اللهوردىيور و همكاران (عمبا) جستجوگرى و كنجكاوى را عمدهترين عوامل كشيده شدن به طرف مواد مخـدر در

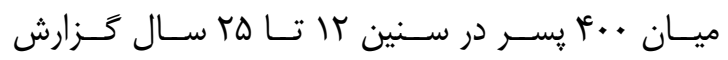
نمودند.(م) تفاوت در علت اصلى شروع مصرف مواد مخدر

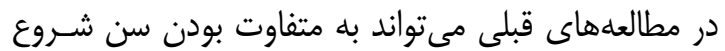
مصرف مواد مرتبط باشد.

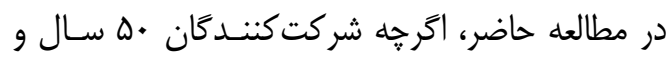

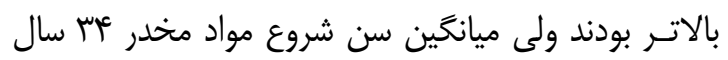

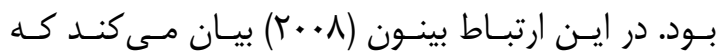

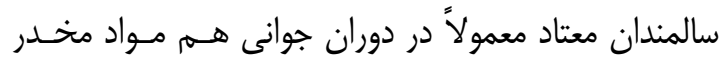

بيشترين علل گرايش به مـواد مخــدر در سـالمندان

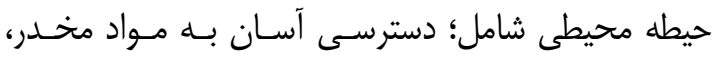

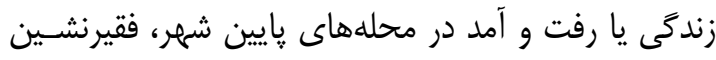

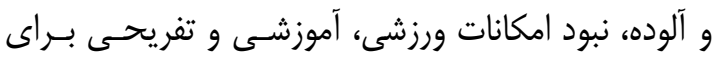

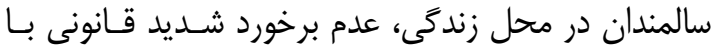
تبادل مواد مخدر و وجود دوستان صميمى معتاد بـهـ مــواد مخدر يا داروهاى غيرمجاز بود (جدول شماره سّ).

\section{جدول ب- ميانكَين نمره علل تَرايش به مواد مخدر در سالمندان به تفكيك حيطهها}

\begin{tabular}{|c|c|}
\hline ميانگين土|نحراف معيار & حيطهها \\
\hline س & خانوادگى \\
\hline$r / V) \pm 1 / r q$ & روانى \\
\hline$r / \cdot \varphi \pm 1 / 4 \mu$ & محيطى \\
\hline$r / T q \pm 1 / r V$ & فردى \\
\hline$r / .9 \pm 1 / r \mu$ & مذهبى \\
\hline$r / \Delta V \pm I / Y r$ & كل \\
\hline
\end{tabular}

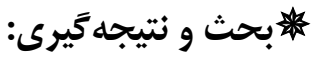

تنايج مطالعه حاضر نشان داد كه اكثريـت سـالمندان، تريـاك مصـرف نمـوده و روش تـرك دارويسى را تجربــهـ

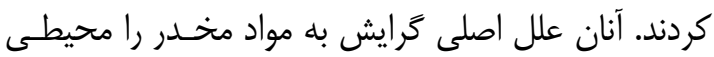

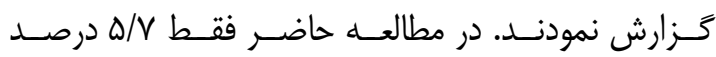

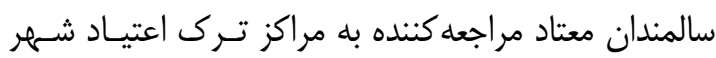
قزوين را زنان تشكيل مىدادنـــ. براسـاس آمـار سـازمان

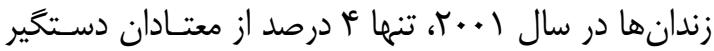

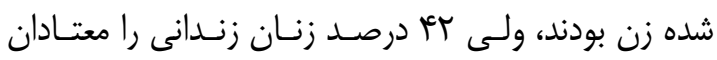

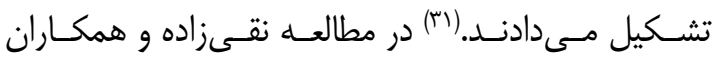

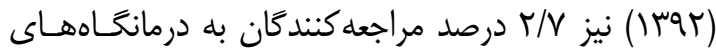

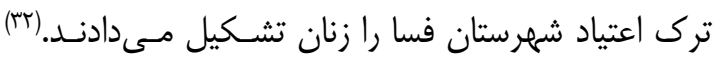

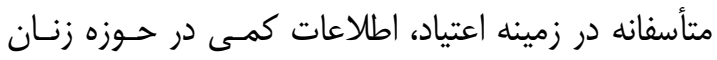

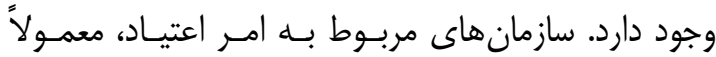

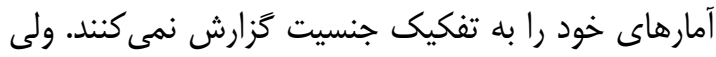
بههر حال، بهدليل بافت فرهنحَى موجـود در كشـور مـا،

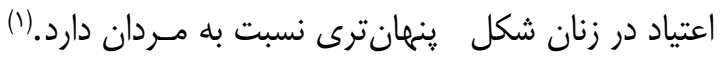

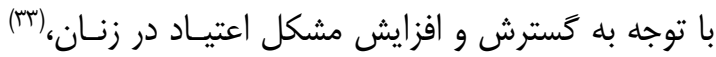




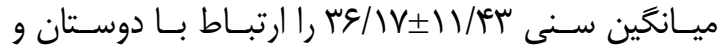
آشنايان معتاد، شركت در مهمانى و علاقه به مصرف مواد

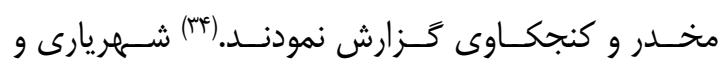

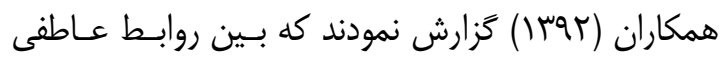
ميان اعضاى خانواده و گرايش به اعتياد دانشجويان رابطه

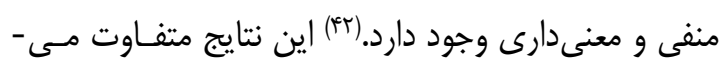

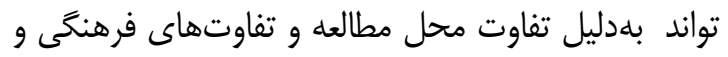

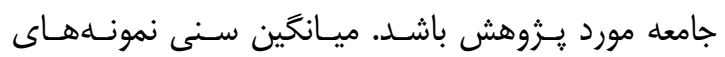
بررسى شده در مطالعهاى ززارش شده بلطور معنـادارى يإيينتر از نمونه مطالعه حاضر بود.

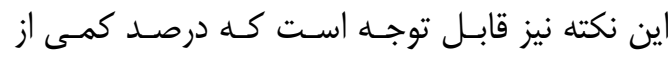

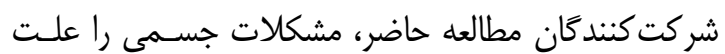
كرايش به مواد مخدر معرفى كردند. در حالى كه بسيارى از

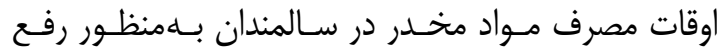

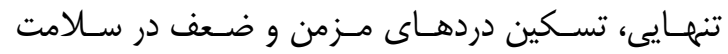

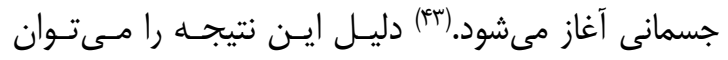

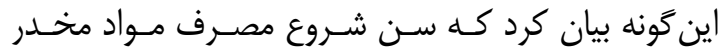

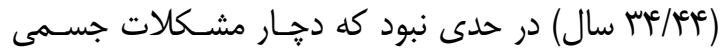

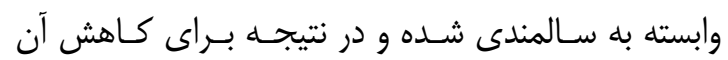
تمايل به مصرف مواد مخدر داشته باشند. از محدوديتهاى اين مطالعه مىتوان به ايـن مسـئله اشاره كرد كه نمونههاى مطالعه سالمندانى بودند كه جهت ترك مصرف مواد مخدر بلهصورت خود معـرف بـه مراكـز

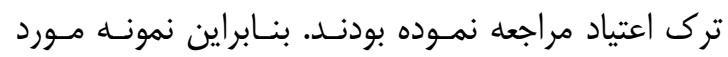
مطالعه در اين يزوهش نمىتواند نمايان گر كل افراد جامعه

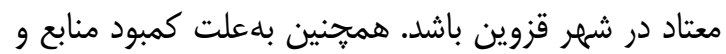

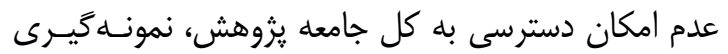

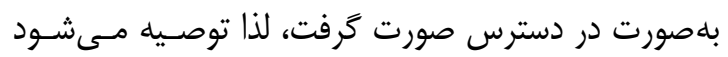
مطالعهاى بعدى با استفاده از نمونه يَيرى تصادفى از كل

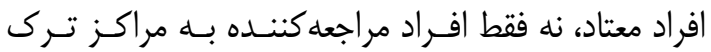

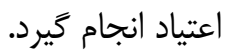
توصيه مىشود جهت ييشخيرى از اعتيـاد سـالمندان،

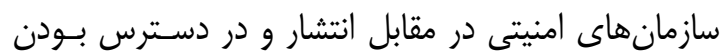
مواد مخدر برخورد شديد و قانونى نموده و سياست كَز اران

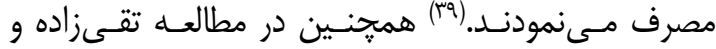

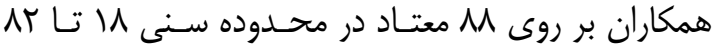
سال مراجعه كننده به مراكز ترك اعتياد شهر فسا، ميانگين

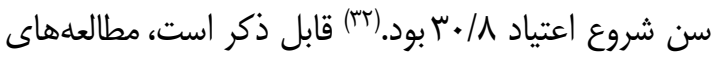
داخلى در ارتباط با اعتياد سالمندان بسيار اندك بـوده و در

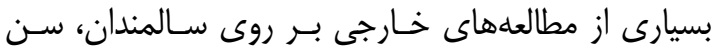
شروع مصرف مواد مخدر ذكر نشده است. ايـن نكتـهـ نيـز

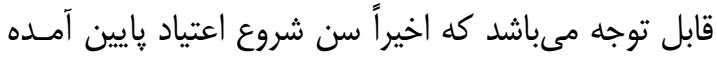

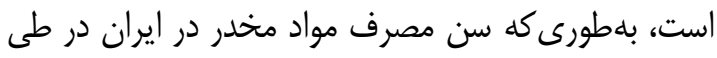

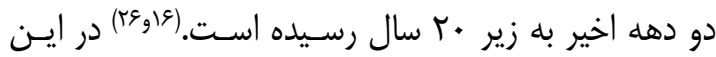

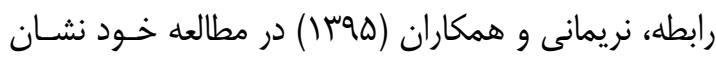

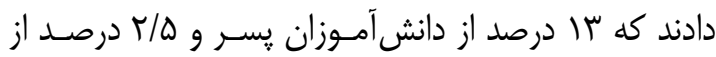
دانشآموزان دختر مقطع متوسطه شهمر سـمنان، حـداقل

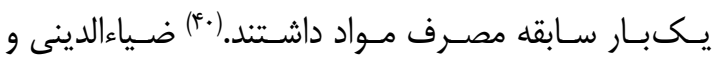

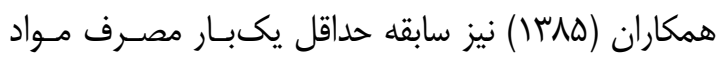

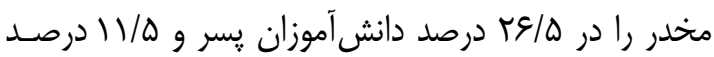
دانش آموزان دختر سال آخر دبيرستان و ييش دانشـاهـى درانى شهر كرمان كزارش نمودند كه نشان دهنــده رِايين آمـدن سن شروع مصرف مواد مخدر در سال هاى اخير مىباشد. (أ)

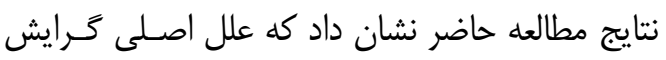
به مواد مخدر از ديدكاه سالمندان مراجعه كننده بــهـ مراكـز ترك اعتياد شهر قزوين، محيطى (دسترسـى آسـان، نبـود

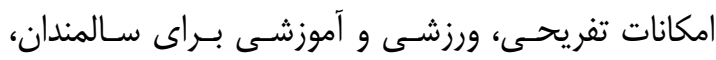

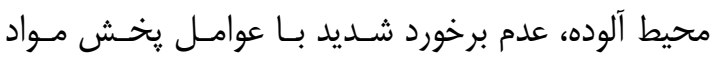

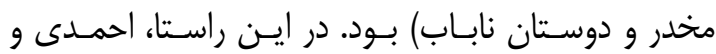

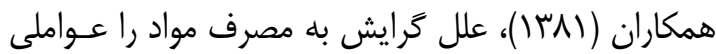

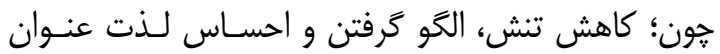

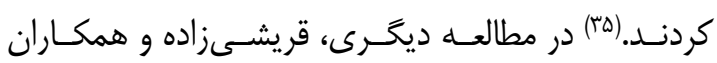

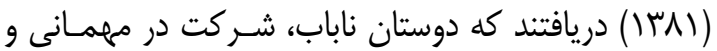

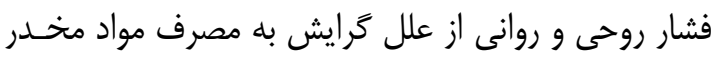

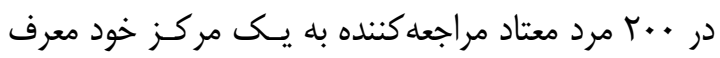

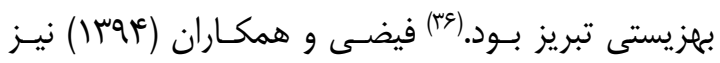

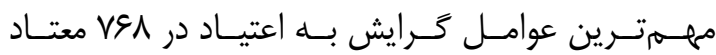

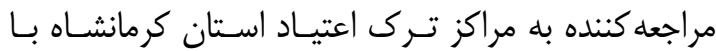


characteristics and family functioning with mental health in addicts. J Qazvin Univ Med Sci 2014; 18(2): 59-66. [In Persian]

7. Sarrami H, Ghorbani M, Minooei M. Survey of four decades of addiction prevalence researches in Iran. J Res Addict 2013; 7(26): 29-52. [In Persian]

8. Chhatre S, Cook R, Mallik E, Jayadevappa $\mathrm{R}$. Trends in substance use admissions among older adults. BMC Health Serv Res 2017; 17(1): 584. doi: 10.1186/s12913-017-2538-z. 9. Wang YP, Andrade LH. Epidemiology of alcohol and drug use in the elderly. Curr Opin Psychiatry 2013; 26(4): 343-8. doi: 10.1097/ YCO.0b013e328360eafd.

10. Asadollahi A, Baratvand M, Valizade Sh, Havasi A. Drug and solvent abuse among Ahwaz's elderlies. Salmand Iran J Ageing 2007; 2(3): 346-51. [In Persian]

11. National survey of substance abuse Treatment servics(N_SSAT).Office of aplide studies. Substance Abuse and Mental Health Services Administration. Data on Substance Abuse Treatment Facilities D 2006. https://www.samhsa.gov/.8/23/2017.

12. Ryan RM, Deci EL. From ego-depletion to vitality: Theory and findings concerning the facilitation of energy available to the self. Soc Personal Psychol Compass 2008; 2: 70217. doi: 10.1111/j.1751-9004.2008.00098.x.

13. Razzaghi EM, Rahmani A, Hossein M, Madani S, Chattergee A. Rapid situation assessment (RSA) of drug abuse in Iran (1998-1999). Prevention Department, State Welfare Organization, Ministry of Health, I.R. of Iran. United Nations International Drug Control Program, https://www.undoc. org/pdf/iran/publications/RSA2000SUMMA RY.pdf Updated in: 1999.

14. Rehm J, Room R, Graham K, Monteiro M, Gmel G, Sempos CT. The relationship of

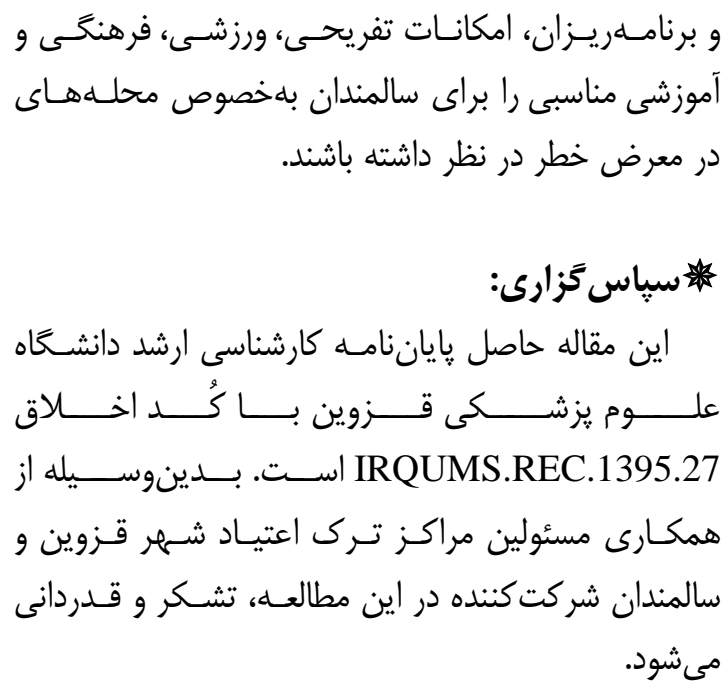

1. Najari $F$. The evaluation of addiction in female addicts admitted to detoxification centers in Tehran during 1384 and 1385. J Med Council I.R.I. 2008; 25(4): 457-62. [In Persian]

2. Vaezi K, Fallahi-Khoshknab M. Spiritual Coping against the desire of re-using drug. J Qual Res Health Sci 2018; 6(4): 449-60.

3. Noël $X$, Brevers D, Bechara A. A neurocognitive approach to understanding the neurobiology of addiction. Curr Opin Neurobiol 2013; 23(4): 632-8. doi: 10.1016/ j.conb.2013.01.018.

4. Noori R, Narenjiha H, Aghabakhshi H, Habibi G, Khoshkrood Mansoori B. Methadone maintenance therapy outcomes in Iran. Subst Use Misuse 2012 47(7): 767-73. doi: 10.3109/10826084.2010.517726.

5. Asghari E, Ebrahimi H, Chehreh Barghi V, Molaee F. Comparing the related sociodemographical factors in the first and recurrent quitting of drug addiction. J Health Care 2012; 14 (1 and 2): 23-9.

6. Ahmadi KH, Alizadehgoradel J, Rezazadeh M, Jabraeili SH. Association of personality 
average volume of alcohol consumption and patterns of drinking to burden of disease: an overview. Addiction 2003; 98(9): 1209-28. doi: 10.1046/j.1360-0443.2003.00467.x.

15. Pinquart M. Moderating effect of dispositional Resilience on association between hassles and Psychological distress. J Appl Dev Psychol 2009; 3(1): 1-8.

16. Purehsan S, Falsafinejad M, Delavar A, Farokhi N, Borjali A. Metacognitive beliefs and students' tendency toward drug abuse and cross-level effect of school-bounding. J Pract Clin Psychol 2016; 4(1): 33-43.

17. Roshani B, Jalali A, Bidhendi S, Ezzati E, Mahboubi M. Study the causes of relapse among Iranian drugs users in Kermanshah. Life Sci J 2014; 11(1): 66-71.

18. Simoni-Wastila L, Yang HK. Psychoactive drug abuse in older adults. Am J Geriatr Pharmacother 2006; 4(4): 380-94.

19. Smith C. Theorizing religious effects among American adolescents. J Sci Stud Relig 2003; 42(1): 1-30.

20. Latest statistics on Iran's elderly population Available at: www.mojnews .com. Updated in 2018.

21. Springer FJ, Sale E, Hermann J, Sambrano S, Kasim R, Nistler M. Characteristics of effective substance abuse prevention programs for high-risk youth. J Prim Prev 2004; 25(2): 171-94.

22. Bachi K, Sierra S, Volkow ND, Goldstein RZ, Alia-Klein N. Is biological aging accelerated in drug addiction? Curr Opin Behav Sci 2017; 13: 34-9. doi: 10.1016/j. cobeha.2016.09.007.

23. Crome I, Sidhu H, Crome P. No longer only a young man's disease-Illicit drugs and older people. J Nutr Health Aging 2009; 13(2): 141-3.

24. Colliver JD, Compton WM, Gfroerer JC,
Condon T. Projecting drug use among aging baby boomers in 2020. Ann Epidemiol 2006; 16(4): 257-65. doi: 10.1016/j.annepidem. 2005.08.003.

25. Wu LT, Blazer DG. Illicit and nonmedical drug use among older adults: a review. J Aging Health 2011; 23(3): 481-504. doi: 10. 1177/0898264310386224.

26. Moy I, Crome P, Crome I, Fisher M. Systematic and narrative review of treatment for older people with substance problems. Eur Geriatr Med 2011; 2(4): 212-36.

27. Rosen D, Smith ML, Reynolds CF 3rd. The prevalence of mental and physical health disorders among older methadone patients. Am J Geriatr Psychiatry 2008; 16(6): 488-97 doi: 10.1097/JGP.0b013e31816ff35a.

28. Lawshe $\mathrm{CH}$. Qualitative approach to content validity. Personnel Psychology 1975; 28: 563-75. doi: 10.1111/j.1744-6570.1975. tb01393.x.

29. Jay Lynn S, Surya Das L, Hallquist MN, Williams JC. Mindfulness, acceptance, and hypnosis: cognitive and clinical perspectives. Int J Clin Exp Hypn 2006; 54(2): 143-66. doi: 10.1080/00207140500528240.

30. Yen CF, Hwang AW, Liou TH, Chiu TY, Hsu HY, Chi WC, et al. Validity and reliability of the functioning disability evaluation scale-adult version based on the WHODAS 2.0-36 items. J Formos Med Assoc 2014; 113(11): 839-49. doi: 10.1016/ j.jfma.2014.08.008.

31. Ahmadi J, Fakoor A, Pezeshkian P, Khoshnood R, Malekpour A. Substance use among Iranian psychiatric inpatients. Psychol Rep 2001; 89(2): 363-5. doi: 10.2466/pr0. 2001.89.2.363.

32. Naghizadeh MM, Rezaei Z, Zarei F, Firoozi E, Ahmadi D. Pattern of illegal drug use in women referred to Substance Abuse 
Control Clinic in Fasa, Iran (2009-2011). J Fasa Univ Med Sci 2014; 3(4): 305-11. [In Persian]

33. Tuchman E. Women and addiction: the importance of gender issues in substance abuse research. J Addict Dis 2010; 29(2): 127-38. doi: 10.1080/10550881003684582.

34. Feyzi H, Vaisi-Raygani AA, Abdi A, Shakeri J, Mardokhian M. The predisposing factors for drug abuse in viewpoints of referrers to addiction treatment centers in Kermanshah. Iran J Rehabil Res Nursing 2015; 2(6): 48-56. [In Persian]

35. Ahmadi J, Hasani M. Prevalence of substance use among Iranian high school students. Addict Behav 2003; 28(2): 375-9 doi: 10.1016/S0306-4603(01)00246-5.

36. Ghoreishizadeh SMA, Torabi K. Factors Contributing to illicit substance dependence among treatment seeking addicts in Tabriz. Iran J Psychiatry Clin Psychol 2002; 8(1): 218. [In Persian]

37. Rahmati MM. The factors affecting drug abuse among addicted women. J Res Addict 2002; 1(1). [In Persian]

38. Allahverdipour $\mathrm{H}$, Farhadinasab A, Bashirian S, Mahjoob H. Pattern and inclination of adolescents towards substance abuse. J Shahid Sadoughi Univ Med Sci 2008; 15(4): 35-42. [In Persian]

39. Beynon CM. Drug use and ageing: older people do take drugs! Age Ageing 2009; 38(1): 8-10. doi: 10.1093/ageing/afn251.

40. Narimani M, Rajabpour M, Ahmadi O, Yaghooti Zarghar H, Rostamoghli Z. Prevalence and factors associated with drug abuse among high school students in Semnan. J School Psychol 2017; 5(4): 132-45. [In Persian]

41. Zaiadinin H, Zarezadeh A, Heshmati F. The prevalence of drug abuse and addiction and related factors in the final year students. J Kerman Univ Med Sci 2006; 2(3): 84-94. [In Persian]

42. Shahriari S, Dastjerdi R, Hojjatzadeh N, Kekhal R, Ramazani AA. Family function on tendency students towards addiction and substance abuse. J Zabol Univ Med Sci 2014; 5(4): 59-67. [In Persian]

43. Zarghami M. Iranian common attitude toward opium consumption. Iran J Psychiatry Behav Sci 2015; 9(2): e2074. doi: 10.17795/ ijpbs2074. 